Death or life threatening side effects were not seen during follow-up. ABA is an acceptable treatment option in DMARD resistant biologic naive RA patients. Disclosure of Interest: None declared

DOI: 10.1136/annrheumdis-2017-eular.4082

\section{SAT0217 EARLY PATIENT-REPORTED OUTCOMES AND CLINICAL OUTCOMES WITH ABT-494 IN PATIENTS WITH ACTIVE RHEUMATOID ARTHRITIS WHO ARE INADEQUATE RESPONDERS TO METHOTREXATE OR TUMOR NECROSIS FACTOR INHIBITORS: POST-HOC ANALYSIS OF PHASE 2 RANDOMIZED CONTROLLED TRIALS}

V. Strand ${ }^{1}$, N. Tundia ${ }^{2}$, I.H. Song ${ }^{2}$, S. Meerwein ${ }^{2}$, J. Lin ${ }^{2}$, N. Chen ${ }^{2}$, A. Friedman ${ }^{2} .{ }^{1}$ Stanford University, Palo Alto; ${ }^{2}$ AbbVie Inc., North Chicago, United States

Background: Janus kinase (JAK) inhibitors are being evaluated for treatment of active rheumatoid arthritis (RA). Understanding their onset of action on patient reported outcomes (PROs) and clinical endpoints in RA patients (pts) is limited. Objectives: To assess onset of benefit with ABT-494, a selective JAK1 inhibitor vs placebo (PBO) in RA pts with active disease $>3$ months in 2 randomized controlled trials (RCTs) evaluating safety and efficacy of ABT-494. M13-537 (NCT02066389) included pts who were inadequate responders to methotrexate (MTX-IR) and M13-550 (NCT01960855) to tumor necrosis factor inhibitors (TNF-IR).

Methods: Data were analyzed separately for each RCT in pts who received $6 \mathrm{mg}$ or $12 \mathrm{mg}$ bid ABT-494 or PBO. Analyses included cumulative assessment of PROs such as patient global assessment of disease activity (PtGA), pain Visual Analogue Scale (VAS) and Health Assessment Questionnaire Disability Index (HAQ-DI) in terms of Routine Assessment of Patient Index Data 3 (RAPID3) scores, and clinical outcomes such as DAS28 (CRP) and CDAl. To assess onset and maintenance of effect, the number of pts whose improvements met or exceeded minimal important differences (MID) RAPID3: reduction $\geq 3.6$; DAS28: reduction $\geq 1.2$; CDAl: reduction $\geq 11.0$ and were calculated at weeks 2 and 12 . Additionally, Kaplan-Meier (KM) analysis estimated mean time to achievement of RAPID3, DAS28 and CDAI MID. Non-responder imputation accounted for missing data.

Results: In M13-537 (N=150 pts) and M13-550 (N=166 pts) RCTs, significantly more pts in ABT-494 12mg groups reported improvements $>$ MID in RAPID3 vs PBO at Wk 2: $68 \%$ vs $30 \%$ and $73 \%$ vs $38 \%$, respectively (Table). In M13-537, significantly more pts receiving ABT-494 $6 \mathrm{mg}$ BID vs PBO (54\% vs $30 \%)$ had improvements $>$ MID in RAPID3. These responses were sustained throughout both trials in pts receiving 12mg ABT-494 (M13-537: 80\%; M13-550: 71\%). Significantly more pts achieved and maintained changes $\geq$ MID in DAS28 in both RCTs and in CDAl in M13-550. Based on KM analyses, in M13-537, estimated mean time ( \pm SE) to achievement of RAPID3 MID was shorter for both ABT-494 doses vs PBO (12mg: $3.9 \pm 0.5$ weeks; $6 \mathrm{mg}: 3.9 \pm 0.4$ weeks; PBO $6.0 \pm 0.6$ weeks). Similarly, estimated mean time to these responses was shorter with both ABT-494 doses vs PBO (12mg: $3.6 \pm 0.4$ weeks; $6 \mathrm{mg}: 4.9 \pm 0.6$ weeks; PBO: $6.6 \pm 0.6$ weeks) in M13-550, although it was underestimated due to censoring.

\begin{tabular}{|c|c|c|c|c|c|c|}
\hline \multirow[b]{2}{*}{$n(\%)$} & \multicolumn{3}{|c|}{ M13-537 } & \multicolumn{3}{|c|}{ M13-550 } \\
\hline & $\begin{array}{c}\text { ABT-494 6mg } \\
N=50\end{array}$ & $\begin{array}{c}A B T-49412 \mathrm{mg} \\
\mathrm{N}=50\end{array}$ & $\begin{array}{l}\text { PBO } \\
\mathrm{N}=50\end{array}$ & $\begin{array}{c}\text { ABT-494 6mg } \\
N=55\end{array}$ & $\begin{array}{c}\text { ABT- } 49412 \mathrm{mg} \\
\mathrm{N}=55\end{array}$ & $\begin{array}{l}\text { PBO } \\
\mathrm{N}=56\end{array}$ \\
\hline \multicolumn{7}{|c|}{ RAPID3: 2MID } \\
\hline Week 2 & $27(54)^{0}$ & $34(68)^{b}$ & $15(30)$ & $25(45)$ & $40(73)^{\mathrm{b}}$ & $21(38)$ \\
\hline Week 12 & $32(64)$ & $40(80)^{b}$ & $24(48)$ & $35(64)^{a}$ & $39(71)^{b}$ & $23(41)$ \\
\hline \multicolumn{7}{|c|}{ DAS28: $\geq$ MID } \\
\hline Week 2 & $26(52)^{\circ}$ & $27(54)^{b}$ & $9(18)$ & $27(49)^{\circ}$ & $36(65)^{b}$ & $14(25)$ \\
\hline Week 12 & $37(74)^{\circ}$ & $44(88)^{\mathrm{b}}$ & $22(44)$ & $32(58)$ & $38(69)^{\mathrm{b}}$ & $23(41)$ \\
\hline \multicolumn{7}{|c|}{ CDAI: $\geq M I D$} \\
\hline Week 2 & $25(50)$ & $25(50)$ & $17(34)$ & $33(60)^{\circ}$ & $33(60)^{\mathrm{b}}$ & $21(38)$ \\
\hline Week 12 & $36(72)^{\circ}$ & $42(84)^{b}$ & $26(52)$ & $39(71)$ & $42(76)^{b}$ & $29(52)$ \\
\hline
\end{tabular}

Conclusions: Patients treated with ABT-494 showed fast clinically meaningful improvements in patient reported disease activity, pain, physical function cumulatively assessed as RAPID3, as well as clinical outcomes DAS28 and CDAI, as early as week 2 and sustained through week 12 in both MTX-IR and TNF-IR populations.

Acknowledgements: Financial support for the study and medical writing support (Joann Hettasch, Fishawack Group, Conshohocken, PA) was provided by AbbVie. AbbVie participated in interpretation of data, review, and approval of the abstract. All authors contributed to development of the abstract and maintained control over final content.

Disclosure of Interest: V. Strand Consultant for: AbbVie, Amgen, AstraZeneca, BMS, Celgene, Genentech, GSK, Janssen, Lilly, Novartis, Pfizer, Regeneron, Sanofi, and UCB; Ad boards: AbbVie, Amgen, AstraZeneca, BMS, Celgene, Genentech, GSK, Janssen, Lilly, Novartis, Pfizer, Regeneron, Sanofi, and UCB, N. Tundia Shareholder of: AbbVie, Employee of: AbbVie, I. H. Song Shareholder of: AbbVie, Employee of: AbbVie, S. Meerwein Shareholder of: AbbVie, Employee of: AbbVie, J. Lin Shareholder of: AbbVie, Employee of: AbbVie, N. Chen Shareholder of: AbbVie, Employee of: AbbVie, A. Friedman Shareholder of: AbbVie, Employee of: AbbVie
DOI: 10.1136/annrheumdis-2017-eular.1143

\section{SAT0218 EFFECT OF TOCILIZUMAB IN DMARD-NAÏVE EARLY RHEUMATOID ARTHRITIS PATIENTS ON HEALTH-RELATED QUALITY OF LIFE: RESULTS OF THE U-ACT-EARLY TRIAL}

X.M. Teitsma ${ }^{1}$, J.W. Jacobs ${ }^{2}$, P.M. Welsing ${ }^{2}$, A. Pethö-Schramm ${ }^{3}$, M.E. Borm ${ }^{4}$ J.M. van Laar ${ }^{1}$, F.P. Lafeber ${ }^{1}$, J.W. Bijlsma ${ }^{1},{ }^{1}$ Rheumatology and Clinical Immunology; ${ }^{2}$ UMC Utrecht, Utrecht, Netherlands; ${ }^{3} \mathrm{~F}$. Hoffmann-La Roche, Basel, Switzerland; ${ }^{4}$ Roche Nederland B.V., Woerden, Netherlands

Background: Tocilizumab (TCZ), a humanized interleukin-6 receptor inhibitor, has been shown effective in suppressing symptoms of rheumatoid arthritis (RA). In U-Act-Early, a significantly greater proportion of patients with early RA who initiated TCZ (84\%) or TCZ plus MTX therapy (86\%) achieved sustained remission (Disease Activity Score assessing 28 joints (DAS28) $<2.6$ with $\leq 4$ swollen joints for $\geq 24$ weeks), when compared to those initiating MTX (44\%). [1]

Objectives: To determine the effect of treat-to-target TCZ therapy, with or without MTX, on health-related quality of life (HRQoL) in disease modifying anti-rheumatic drugs (DMARD)-naïve patients with early RA.

Methods: Patients $(n=317)$ were randomized to initiate TZC, TCZ+MTX or MTX therapy and treated according to a step-up strategy. TCZ was given $(8 \mathrm{mg} / \mathrm{kg})$ every 4 weeks and MTX (oral) was started at $10 \mathrm{mg} /$ week and increased with steps of $5 \mathrm{mg}$ steps 4 weekly up to $30 \mathrm{mg} /$ week (or maximum tolerable dose) until remission. If after 20 weeks remission was not achieved, hydroxychloroquine was added and discontinued 12 weeks thereafter if the target still was not achieved. Patients who originally initiated monotherapy then switched to TCZ+MTX therapy and those already on this combination therapy switched to a tumour necrosis factor inhibitor. To evaluate the effect of TCZ on HRQoL, we used the 36-item Short-Form (SF-36), which can be summarized into a physical (PCS) and mental (MCS) component score. HRQoL was measured at baseline and after 12, 24, 52, and 104 weeks. A linear mixed effect model with a random intercept was used to evaluate differences between treatment strategies over time with visit (time), strategy, baseline SF-36 score, baseline DAS28 level (i.e., DAS28 $<5.1$ or $\geq 5.1$ ) and centre as fixed effects. The proportions of patients exceeding the minimum clinically important differences (MCID, $\geq 2.5$-point increase from baseline) were tested for significance using the two-sided Pearson's chi-squared test.

Results: We found significantly greater improvements over time in the SF-36 PCS in patients initiating treatment with TCZ (TCZ vs MTX; $\mathrm{p}=0.041, \mathrm{TCZ}+\mathrm{MTX}$ vs MTX; $p=0.011$, Fig. 1). For the SF-36 MCS, no significant differences over time were noted between the treatment arms $(p>0.11)$. A significantly higher proportion of patients initiating treatment with TCZ $(76 \% ; p=0.016,89 \% ; p=0.030)$ or TCZ+MTX (73\%; $p=0.049,89 \% ; p=0.027)$ achieved MCID in the SF-36 PCS at week 12 and week 52, when compared to those initiating treatment with MTX (59\% and $73 \%$, respectively). Although the proportions of patients achieving MCID in the SF-36 MCS were numerically higher in the TCZ arms, no significant differences were found $(p \geq 0.06)$.

Fig. 1: Mean (SE) change from baseline in SF-36 PCS (A) and SF-36 MCS (B)
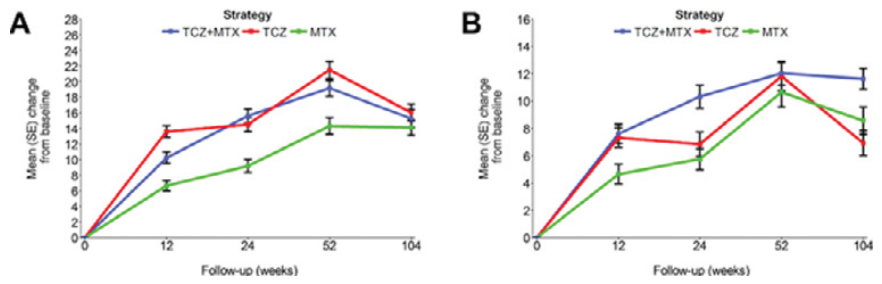

Conclusions: Initiation of TCZ, with or without MTX, at start of therapy resulted in statistically significant and clinically relevant improvements in the HRQoL when compared to initiation of MTX alone and may be considered as a valuable treatment strategy in DMARD-naïve patients with early RA.

\section{References:}

[1] Bijlsma JW, Welsing PM, Woodworth TG, et al. Early rheumatoid arthritis treated with tocilizumab, methotrexate, or their combination (U-Act-Early): a multicentre, randomised, double-blind, double-dummy, strategy trial. Lancet 2016; 388:343-55

Disclosure of Interest: X. Teitsma: None declared, J. Jacobs: None declared, P. Welsing: None declared, A. Pethö-Schramm Employee of: Employee of F.Hoffmann-La Roche, M. Borm Employee of: Roche Nederland B.V., J. van Laar Consultant for: Received fees from MSD, Pfizer, Roche, Eli Lilly and BMS, F. Lafeber: None declared, J. Bijlsma Grant/research support from: Received research grants (to his department) and consultancy fees from AbbVie, BMS, Crescendo, MSD, Mundipharma, Pfizer, Roche, Sun and UCB

DOI: 10.1136/annrheumdis-2017-eular.2190 